Communication

\title{
Intact leptin receptor signalling is not required for the sustained weight loss and appetite suppression induced by Roux-en-Y gastric bypass surgery
}

\author{
Mohammed K. Hankir ${ }^{1, *}$, Laura Rotzinger ${ }^{1}$, Arno Nordbeck ${ }^{1}$, Caroline Corteville ${ }^{1}$, Annett \\ Hoffmann $^{1}$, Christoph Otto ${ }^{1}$ and Florian Seyfried ${ }^{1, *}$ \\ 1 Department of General, Visceral, Vascular and Pediatric Surgery, University Hospital Wuerzburg, \\ Wuerzburg 97080, Germany \\ * Correspondence to: hankir m@ukw.de (M.K.H) and seyfried f@ukw.de (F.S.)
}

\begin{abstract}
Leptin is the archetypal adipokine that promotes a negative whole-body energy balance largely through its action on brain leptin receptors. As such, the sustained weight loss and food intake suppression induced by Roux-en-Y gastric bypass (RYGB) surgery have been attributed to enhancement of endogenous leptin action. We formally revisited this idea in Zucker Fatty falfa rats, an established genetic model of leptin receptor deficiency, and carefully compared their body weight, food intake and oral glucose tolerance after RYGB with that of sham-operated falfa (obese) and sham-operated $f a /+$ (lean) rats. We found that RYGB rats sustainably lost body weight, which converged with that of lean rats and was $25.5 \%$ lower than that of obese rats by the end of the 4 week study period. Correspondingly, daily food intake of RYGB rats was similar to that of lean rats from the second postoperative week, while it was always at least $33.9 \%$ lower than that of obese rats. Further, oral glucose tolerance of RYGB rats was normalized at the forth postoperative week. These findings assert that leptin is not an essential mediator of the sustained weight loss and food intake suppression as well as the improved glycemic control induced by RYGB, and instead point to additional circulating and/or neural factors.
\end{abstract}

Keywords: 1. Roux-en-Y gastric bypass surgery; 2. Weight loss; 3. Food intake; 4. Oral glucose tolerance; 5. Leptin; 6. Leptin receptors; 7. Zucker Fatty falfa rats

\section{Introduction}

Bariatric surgery is presently the mainstay treatment option against morbid obesity, with numerous prospective clinical studies showing that Roux-en-Y gastric bypass (RYGB) in particular induces marked and sustained weight loss as well as long-term remission of type 2 diabetes in a majority of cases [1]. Because RYGB reduces stomach size and excludes the duodenum from contact with ingested food, physical restriction and malabsorption of nutrients, respectively, were originally thought to mainly account for its beneficial effects on energy and glucose homeostasis [2]. However, with the aid of robust rodent models of RYGB [3-5], it is becoming increasingly evident that complex molecular and cellular processes are in play postoperatively, better understanding of which may guide the development of more effective appetite suppressing and blood glucose lowering drugs than what are currently available.

Leptin is a 16-kDa endocrine protein mainly released from white adipocytes and circulates in proportion to fat mass, thereby serving as a negative feedback signal to the brain on whole-body 
energy stores [6,7]. Accordingly, leptin-deficient $o b / o b$ mice [8,9] and leptin unresponsive $d b / d b$ mice [10], which lack the intracellular signalling domain unique to leptin b receptors due to an autosomal recessive $\mathrm{G} \rightarrow \mathrm{T}$ point mutation in the leptin receptor gene [11], have severe, hyperphagic obesity as well as hyperglycemia. Moreover, diet-induced obesity is thought to arise from the development of central leptin resistance as a result of complex pro-inflammatory processes that directly interfere with hypothalamic leptin receptor signalling [12-15]. For these reasons, leptin supplementation to $o b / o b$ mice normalizes their body weight, food intake and glycemic control [16,17], whereas leptin sensitizers have taken center stage in obesity drug development [18,19]. While RYGB markedly reduces circulating leptin levels [20-22], even beyond that from chronic caloric restriction-induced weight loss alone [23-28], leptin action might be enhanced postoperatively, thereby preventing the counter-regulatory response to depletion of whole-body energy stores which normally powerfully pressures weight regain [6]. Indeed, the disproportionately reduced circulating leptin levels induced by RYGB may in itself paradoxically restore leptin action by reversing central leptin resistance [29]. The necessity of leptin for the beneficial outcomes of RYGB on energy and glucose homeostasis was originally tested in ob/ob mice [30,31]. The sustained weight loss and food intake suppression induced by RYGB was found to be preserved in one study [31], but not in another [30], although in both studies, RYGB failed to fully improve glycemic control [30,31]. This is consistent with the documented independent effects of leptin in beneficially regulating glucose homeostasis [32]. On the other hand, weight loss and enhanced insulin sensitivity [33], as well as improved fasting blood glucose levels and oral glucose tolerance [34] in $d b / d b$ mice after RYGB appear to be largely intact.

Zucker Fatty fa/fa rats are another genetic model of leptin receptor deficiency since they harbor an autosomal recessive $\mathrm{A} \rightarrow \mathrm{C}$ point mutation at position 880 of the leptin receptor gene, distinct from the $d b / d b$ point mutation, which causes an inhibitory $\mathrm{Glu} \rightarrow$ Ala amino acid substitution at position 269 in the extracellular domain common to all leptin receptor subtypes (a-f) [35-37]. As a result, Zucker Fatty fa/fa rats are obese and hyperlipidemic [38], and exhibit markedly impaired oral glucose tolerance [39] as well as severely diminished responsiveness to exogenous leptin treatment [40,41]. Zucker Diabetic Fatty fa/fa rats, on the other hand, additionally harbor a mutation that reduces insulin promoter activity in pancreatic beta cells [42], rendering them incapable of secreting adequate amounts of insulin and thus genuinely diabetic [43]. Numerous studies have been performed aimed at assessing the metabolic effects of RYGB on both Zucker Fatty fa/fa [44-48] and Zucker Diabetic Fatty $f a / f a[24,49-64]$ rats, but their descriptions on food intake were generally either incomplete $[44-51,54,61,62,64]$ or, in many studies, entirely missing [24,52,53,55-60,63]. Additionally, only a few of these studies incorporated a lean control group in the form of heterozygous Zucker Fatty $f a /+$ rats $[44,46,47,59]$, which is essential if any conclusions are to be drawn about whether RYGB normalizes glycemic control. Surprisingly, all of these studies entirely overlooked the necessity of leptin receptors in the sustained metabolic benefits induced by RYGB, which calls for their reinterpretation. We therefore directly addressed and carefully assessed if the sustained weight loss and food intake suppression as well as improved glycemic control induced by RYGB require intact leptin receptor signalling by using Zucker Fatty $f a / f a$ rats in comparison with both sham-operated Zucker Fatty fa/fa and sham-operated Zucker Fatty fa/+ rats over a 4 week monitoring period. Our findings provide further evidence against leptin being an essential mediator of the two best characterized metabolic benefits induced by RYGB.

\section{Materials and Methods}

Animals 
Two cohorts of male Zucker Fatty $f a / f a$ and Zucker Fatty fa/+ rats were purchased from Charles River, France, aged 6 weeks. The first cohort comprised 12 Zucker Fatty fa/fa rats and 7 Zucker Fatty $f a /+$ rats whereas the second cohort comprised 16 Zucker Fatty fa/fa rats and 5 Zucker Fatty fa/+ rats and were used in a previous study [46]. Because housing and treatment conditions were identical for both cohorts, they were merged for the purposes of this study. Animals were individually housed under ambient humidity and temperature of $22{ }^{\circ} \mathrm{C}$ in a 12-hour light/dark cycle with free access to tap water and Purina 5008 Lab diet (Purina Mills, USA, $16.7 \%$ of calories from fat) unless otherwise stated.

Surgeries

At 12 weeks of age, Zucker fatty fa/fa rats were randomly allocated to RYGB $(n=16)$ or sham $(n=12)$ surgeries with the latter forming the "obese" group. Twelve Zucker fa/+ rats also underwent sham surgeries forming the "lean" group (Figure 1). Rats were food deprived for 6 hours pre-operatively and surgical anesthesia was induced and maintained with an isoflurane/oxygen mixture. Immediately prior to surgery, rats were given $5 \mathrm{mg} / \mathrm{kg}$ carprofen subcutaneously as analgesia. The abdomen was opened using a midline laparotomy and closed using continuous suturing. For the sham surgery, the small bowel and gastro-esophageal junction were mobilized, and a gastrostomy on the anterior wall of the stomach and a jejunostomy with subsequent closure were performed. For the RYGB procedure, the jejunum was transected $16 \mathrm{~cm}$ aboral to the pylorus to create the biliopancreatic limb. The stomach was divided $3 \mathrm{~mm}$ below the gastro-esophageal junction to create a small pouch and the stomach remnant was subsequently closed. The aboral jejunum was anastomosed end-to-side to the small pouch. At the level of the lower jejunum, a 7-mm side-to-side jejuno-jejunostomy between the biliopancreatic limb and the alimentary limb was performed creating a common channel of $25 \mathrm{~cm}$ in length.

Upon recovery from surgeries, rats were placed on a liquid diet for 6 days postoperatively and then returned to their previous solid diet. Food intake was measured daily from postoperative day 6 while body weight was measured daily throughout the 27 monitoring period. All experiments were in compliance with the guidelines on animal welfare of the European Union and reviewed and approved by the Animal Care Committee of the local government of Unterfranken, Bavaria, Germany (License 55.2-2531.01-72/12). 

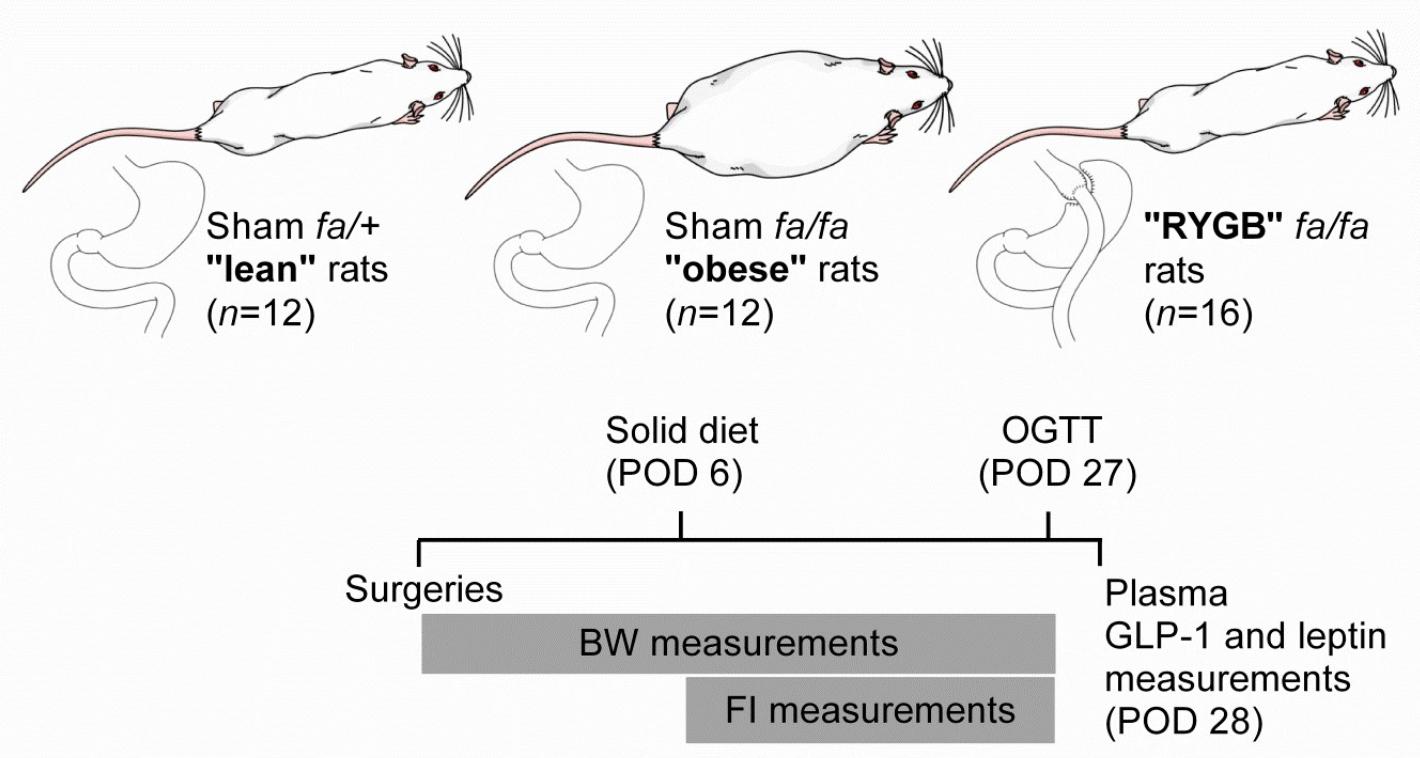

Figure 1. Schematic of experimental design

POD: postoperative day; BW: body weight; FI: food intake; OGTT: oral glucose tolerance test.

Metabolic Measurements

An oral glucose tolerance test (OGTT) was performed at the beginning of the dark cycle on postoperative day 27 in all rats. In order to reduce the stress associated with oral gavage, rats were trained to consume $10 \mathrm{~mL} / \mathrm{kg}$ body weight of a $25 \%$ glucose solution within 10 minutes after an overnight fast on 2 occasions before the OGTT was performed. After an 8-hour overnight fast, blood glucose was measured (Breeze $2 \circledR$ glucometer, Bayer, Zurich, Switzerland) in conscious rats at baseline and 15, 30, 60 and 120 minutes after glucose ingestion. Blood was obtained from the tail vein by a small incision at each time-point. A drop of blood was applied directly to a glucometer, and $100 \mu \mathrm{L}$ was collected in tubes containing EDTA. The plasma fraction was separated by centrifugation at $4{ }^{\circ} \mathrm{C}$ for $8000 \mathrm{rpm}$ and stored at $-80^{\circ} \mathrm{C}$. Total insulin was measured using the Ultrasensitive Rat Insulin ELISA kit (Mercodia AB, Sweden 10-1251-10). Homeostatic model of insulin resistance (HOMA-IR) [65] was calculated by the dividing the product of fasting plasma insulin levels (in $\mu \mathrm{U} / \mathrm{L}$ ) and blood glucose (in $\mathrm{nmol} / \mathrm{L}$ ) by 22.5. Matsuda-DeFronzo insulin sensitivity index (ISI-M) [66] was calculated based on the results of the OGTT as follows:

$$
\mathrm{ISI}-\mathrm{M}=10,000 /\left(G_{0} \times I_{0} \times G_{\text {mean }} \times I_{\text {mean }}\right)^{1 / 2}
$$

Where $G$ and I represents blood glucose (in mmol/dL) and plasma insulin (in $\mathrm{mU} / \mathrm{L}$ ) levels, respectively, and ' 0 ' and 'mean' indicates fasting value and mean value during the OGTT, respectively. 
Tissue Harvesting

At the $28^{\text {th }}$ postoperative day, overnight-fasted animals were sacrificed 45 minutes after a fixed meal of $3 \mathrm{~g}$ Purina 5008 diet by isoflurane overdose. Trunk blood was collected in tubes containing EDTA and a dipeptidyl peptidase-4 inhibitor for GLP-1 and leptin measurements using the Rat GLP-1 ELISA kit (\#EZGLP1T-36 K) from EMD Millipore and the Rat Leptin ELISA kit (ab100773) from abcam, respectively. Epididymal white adipose tissue (eWAT) and retroperitoneal white adipose tissue (rWAT) were dissected, weighed and summed to provide a measure of visceral WAT (vWAT) [67]. Percentage body weight of vWAT was estimated by dividing calculated vWAT weights by body weight.

\section{Statistics}

Statistical analysis was performed using GraphPad PRISM Version $7 \circledR$. Data are expressed as mean \pm standard error of the mean (SEM) unless otherwise stated. A one-way analysis of variance (ANOVA) with Sidak's post hoc test was used to test differences between groups. A Pearson correlation was performed on plasma GLP-1 data vs. average daily food intake and body weight using two-tailed unpaired $t$-test. Statistical significance was determined at $p<0.05$. 


\section{Results}

\subsection{Intact leptin receptor signalling is not required for the sustained weight loss induced by RYGB}

To formally assess the necessity of intact leptin receptor signalling in the sustained negative energy balance induced by RYGB, we performed a detailed analysis of body weight trajectories in Zucker Fatty $f a / f a$ and Zucker Fatty fa/+ rats subjected to either RYGB or sham surgeries (Figure 1).

Importantly, RYGB and obese rats had similar body weights at baseline $(443.7 \pm 2.8 \mathrm{~g}$ vs. $442.3 \pm 6.7 \mathrm{~g}$, respectively; $p=0.99)$, which was significantly higher than that of lean rats (348.8 $\pm 8.1 \mathrm{~g} ; p<0.0001$ for both comparisons) (Figure 2a). From postoperative day 3 onwards, both obese and lean rats progressively gained body weight while RYGB rats lost body weight until postoperative day 6, which then largley stabilized for the remainder of the 27 day monitoring period (Figure 2a). This meant that body weights for RYGB rats were statistically indistinguishable from lean rats from postoperative day 18 onwards and converged by the end of the 27 day monitoring period ( $414.7 \pm$ $12.5 \mathrm{~g}$ vs. $405.0 \pm 10.7 \mathrm{~g}$, respectively; $p=0.99$ ) (Figure $2 \mathrm{a}$ ).

To gain a clearer impression of the magnitude of sustained weight loss induced by RYGB, body weights were expressed relative to baseline for the rats in each group during the 27 day monitoring period (Figure $2 b$ ). This revealed that peak weight loss for RYGB rats at postoperative day 6 was at $-9.7 \pm 0.6 \%$ and stabilized at $-6.5 \pm 2.8 \%$ by postoperative day 27 (Figure $2 b$ ). As expected, obese rats gained body weight at a greater rate than lean rats, diverging signficantly at postoperative day 15 and reaching $+25.9 \pm 0.5 \%$ vs. $+16.1 \pm 1.6 \%$ by postoperative day 27 , respectively (Figure $2 b$ ).

Because the magnitude of sustained weight loss induced by RYGB was less than the 30-40\% typically observed in the clinical setting [1], we also factored in the high rate of weight gain in Zucker Fatty $f a / f a$ rats (Figure $2 \mathrm{c}$ ). This revealed that relative to obese rats at the same time-point, body weights of RYGB rats at postoperative day 27 were $25.5 \pm 2.2 \%$ lower, converging with that of lean rats $(27.3 \pm$ $1.9 \%$ lower; $p=0.81$ ) (Figure $2 \mathrm{c}$ ).

At study end on postoperative day 28, rats were sacrificed and vWAT was dissected and weighed. This revealed that vWAT of obese rats weighed significantly more than that of lean and RYGB rats $(28.4 \pm 1.2 \mathrm{~g}$ vs. $8.0 \pm 0.6 \mathrm{~g}$ and $18.6 \pm 1.0 \mathrm{~g}$, respectively; $p<0.0001$ for both comparisons) (Figure $2 \mathrm{~d}$ ). Interestingly, Sidak post-hoc test also reavealed that vWAT of RYGB rats weighed significantly more than that of lean rats $(p<0.0001)$, suggesting that lean mass of the latter group is greater. When expressed relative to body weight, vWAT of obese rats was significantly higher than that of lean and RYGB rats (5.2 $\pm 0.25 \%$ vs $1.8 \pm 0.05 \%$ and $4.1 \pm 0.2 \%$, respectively; $p<0.0001$ and $p<0.01$ for obese vs lean and obese vs RYGB, respectively), and remained significantly higher for RYGB rats compared with lean rats $(p<0.0001)$ (Figure $2 \mathrm{e})$. This was also reflected both quantitatively and statistically in plasma leptin levels, which were the highest for obese rats $(3.1 \pm 0.11 \mu \mathrm{g} / \mathrm{mL})$ followed by RYGB rats $(1.9 \pm 0.10 \mu \mathrm{g} / \mathrm{mL})$ and then by lean rats $(0.8 \pm 0.07 \mu \mathrm{g} / \mathrm{mL})($ Figure $2 \mathrm{f})$. 
(a)

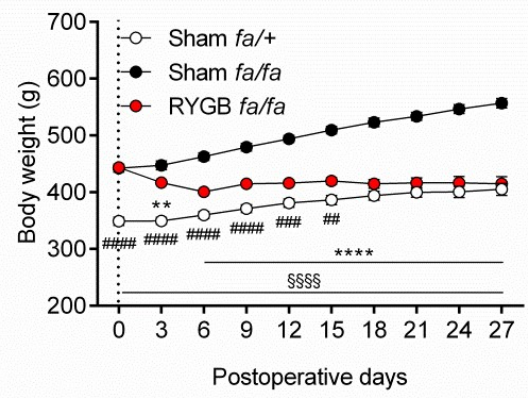

(c)

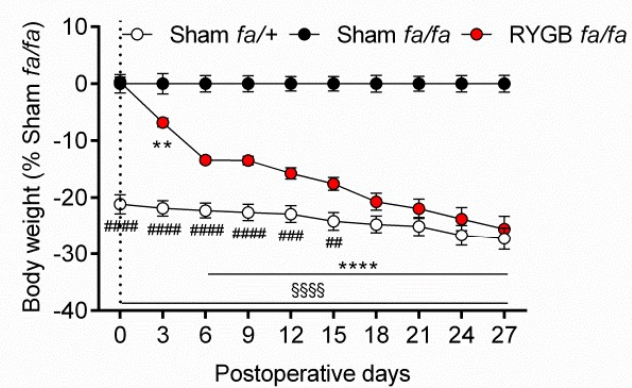

(e)

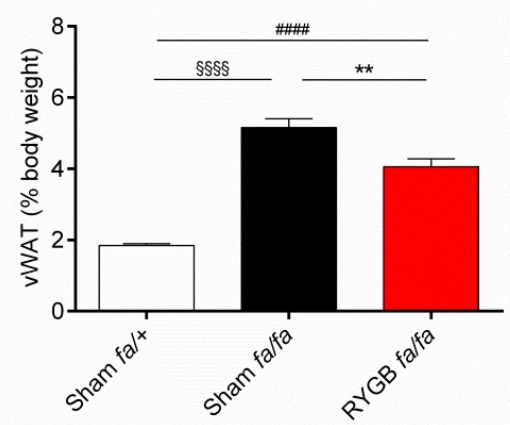

(b)

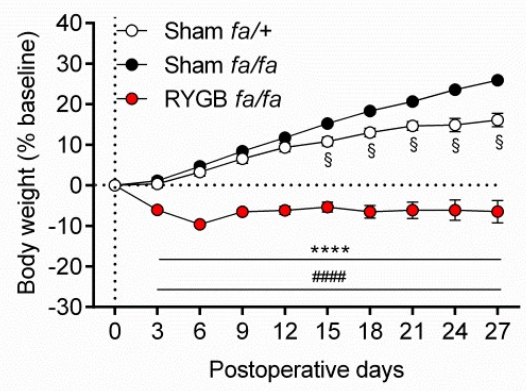

(d)

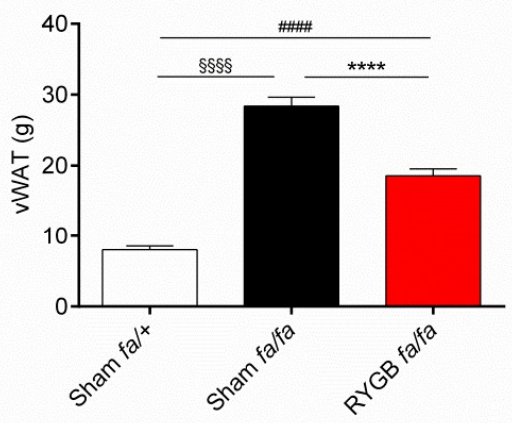

(f)

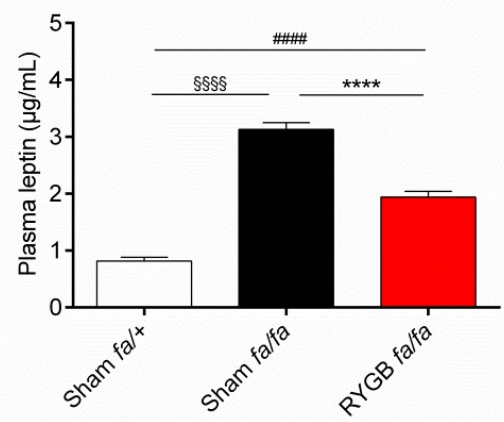

Figure 2. Intact leptin receptor signalling is not required for the sustained weight loss induced by RYGB

(a) Absolute body weight in grams (g), (b) percentage (\%) body weight change relative to baseline and (c) \% body weight of sham-operated fa/fa rats in sham-operated $f a /+$ rats $(n=12)$, sham-operated falfa rats $(n=12)$ and RYGB-operated falfa rats $(n=16)$ during the 27 day monitoring period. (d) Absolute vWAT (eWAT + rWAT) weight, (e) \% vWAT of body weight and (f) fasting plasma leptin concentrations in the rats from (a-c) at the time of sacrifice on postoperative day 28. Data are presented as mean \pm SEM. Statistical significance was determined by one-way ANOVA with Sidak post-hoc test. ${ }^{8 s s} p<0.0001$ for sham-operated $f a /+$ vs. sham-operated $f a l f a$ rats, ${ }^{* *} p<0.01$ and ${ }^{* * * *} p<0.0001$ for RYGB-operated falfa vs. sham-operated falfa rats and ${ }^{* * \sharp} p<0.0001, * * * p<0.001$ and ${ }^{\# \#} p<0.01$ for RYGB-operated falfa vs. sham-operated $f a /+$ rats. 


\subsection{Intact leptin receptor signalling is not required for the sustained food intake suppression induced by RYGB}

Next, to formally assess the necessity of intact leptin receptor signalling in the sustained appetite suppression induced by RYGB, we performed a detailed analysis of food intake in the rats from each group when they were reintroduced to solid diets at postoperative day 6 (Figure 1).

Average daily food intake for RYGB rats was lower than that of lean rats from postoperative days 7-9 (17.6 $\pm 0.7 \mathrm{kcal}$ vs. $24.7 \pm 0.9 \mathrm{kcal}$ per day, respectively; $p<0.0001)$ to postoperative days $13-15$ (20.9 $\pm 0.7 \mathrm{kcal}$ vs. $24.3 \pm 0.5 \mathrm{kcal}$ per day, respecitvely; $p<0.01$ ), but from postoperative days $16-18$ onwards was statistically indistinguishable (Figure 3a). This is possibly due to the extra time needed for healing of the reconfigured gastrointestinal tract in RYGB rats, and might explain the differences in vWAT mass with lean rats (Figure 1d and Figure 1e). Compared with obese rats, however, RYGB rats consumed significantly less food at every time interval during the entire recording period $(p<0.0001)$, so that food intake suppression was sustained until completion of the study at postoperative days $25-27(21.5 \pm 1.8 \mathrm{kcal}$ vs. $32.5 \pm 0.9 \mathrm{kcal}$ per day, respectively; $p<0.0001)$. This equated to $33.9 \pm 5.5 \%$ lower food intake for RYGB rats compared with obese rats (Figure $3 b$ ). Accordingly, cummulative food intake over the recording period for RYGB rats was significantly lowr than that for obese and lean rats $(424.8 \pm 23.8 \mathrm{kcal}$ vs. $676.8 \pm 13.6 \mathrm{kcal}$ and $504.4 \pm 12.2 \mathrm{kcal}$, respectively; $p<0.0001$ for both comparisons) (Figure 3c).

To relate the sustained food intake suppression and weight loss in RYGB rats to a gut-derived satiety factor, we also measured postprandial plasma levels of the anorexigenic gut hormone GLP-1, which are well known to be increased by RYGB [68], at postoperative day 28. Consistent with previous findings in Zucker Fatty falfa rats [45,46], RYGB rats had markedly higher plasma levels of GLP-1 compared with obese and lean rats $(262.0 \pm 19.4 \mathrm{pg} / \mathrm{mL}$ vs. $112.3 \pm 9.7 \mathrm{pg} / \mathrm{mL}$ and $122.8 \pm 16.2 \mathrm{ng} / \mathrm{mL}$, respectively; $p<0.0001$ for both comparisons) (Figure 3d). Further, fasting plasma GLP-1 levels in Zucker Fatty $f a / f a$ rats negatively correlated with food intake at postoperatve days 25-27 ( $r=-0.5$, $p<0.01$ ) (Figure $3 \mathrm{e}$ ) as well as body weight at postoperative day $27(r=-0.63, p<0.001)$ (Figure 3f). 
(a)

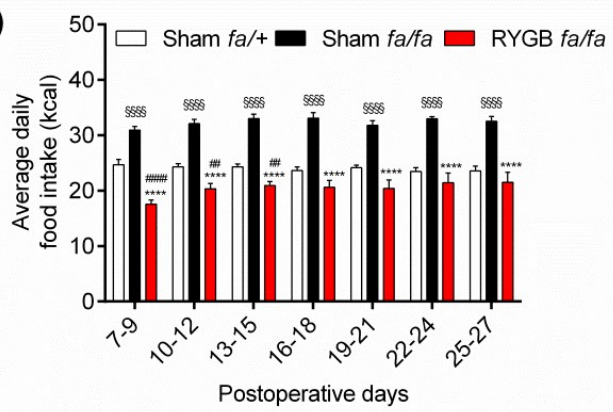

(c)

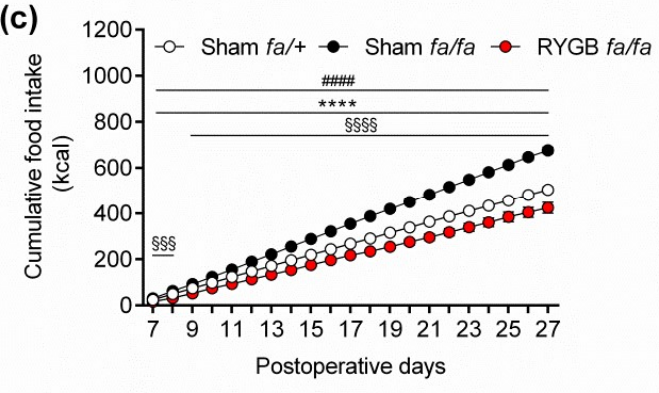

(e)

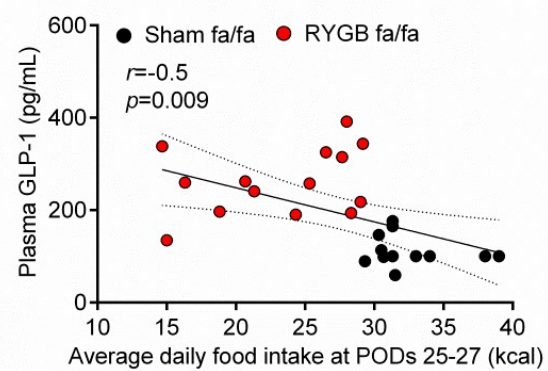

(b)

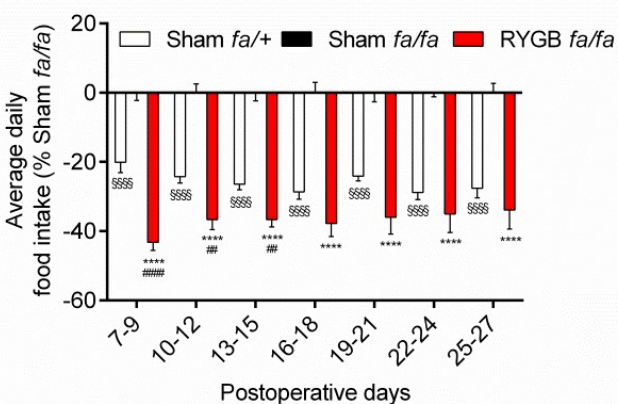

(d)

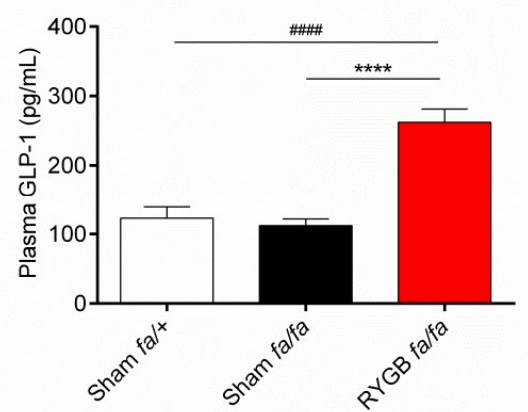

(f)

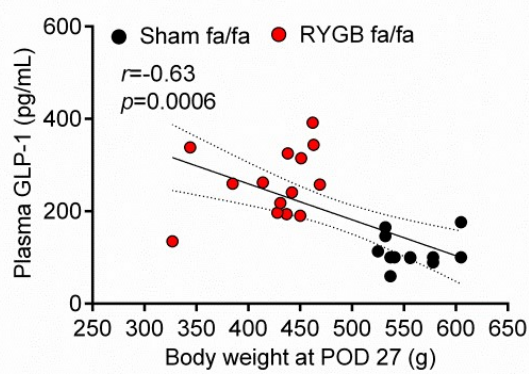

Figure 3. Intact leptin receptor signalling is not required for the sustained food intake suppression induced by RYGB

(a) Average daily food intake in kcal, (b) percentage (\%) average daily food intake relative to sham-operated falfa rats and (c) cumulative food intake in sham-operated fal+ rats $(n=12)$, sham-operated falfa rats ( $n=12)$ and RYGB-operated falfa rats $(n=16)$ during the indicated recording period. (d) Plasma GLP-1 concentrations and (e) its correlation with food intake and (f) body weight in the rats from $(\mathbf{a}-\mathbf{c})$ at the indicated times. Data in $(\mathbf{a}-\mathbf{d})$ are presented as mean \pm SEM. Solid lines in (e and $\mathbf{f}$ ) are the least square fit of data and interrupted lines are $95 \%$ confidence intervals. Statistical significance was determined in (a-d) by one-way ANOVA with Sidak post-hoc test and in (e and $\mathbf{f}$ ) by two-tailed, unpaired $t$-test. $\$ s s s p<0.0001$ for sham-operated $f a /+$ vs. sham-operated $f a / f a$ rats, ${ }^{* * * *} p<0.0001$ for RYGB-operated falfa vs. sham-operated falfa rats and ${ }^{* * \#} p<0.0001$ and ${ }^{*} p<0.01$ for RYGB-operated $f a / f a$ vs. sham-operated $f a /+$ rats. 
Finally, an OGTT was performed at postoperative day 27 to assess the importance of intact letpin receptor signalling in the improved glycemic control induced by RYGB (Figure 1).

Fasting blood glucose levels were slightly but significantly higher for obese compared with lean rats $(105.8 \pm 8.6 \mathrm{mg} / \mathrm{dL}$ vs $80.8 \pm 3.3 \mathrm{mg} / \mathrm{dL}$, respectively; $p=0.01)$, whereas they were statistically indistinguishable for RYGB rats $(92.9 \pm 3.7 \mathrm{mg} / \mathrm{dL})$ compared with both lean $(p=0.23)$ and obese $(p=0.27)$ rats (Figure $4 \mathrm{a})$.

During the OGTT, blood glucose levels peaked for lean rats at $123.5 \pm 5.1 \mathrm{mg} / \mathrm{dL}$ by 15 minutes and then steadily declined to $94.6 \pm 2.9 \mathrm{mg} / \mathrm{dL}$ by 120 minutes (Figure $4 \mathrm{a}$ ). For obese rats, blood glucose levels peaked at $211.4 \pm 15.2 \mathrm{mg} / \mathrm{dL}$ by 30 minutes and remained elevated at $197.7 \pm 15.3 \mathrm{mg} / \mathrm{dL}$ by 60 minutes before eventually declining to $108.0 \pm 4.7 \mathrm{mg} / \mathrm{dL}$ by 120 minutes. The blood glucose excursion curve for RYGB rats during the OGTT was markedly different from both lean and obese rats peaking at $186.3 \pm 12.1 \mathrm{mg} / \mathrm{dL}$ by 15 minutes, then rapidly dropping to $133.6 \pm 8.0 \mathrm{mg} / \mathrm{dL}$ by 30 minutes before declining below baseline values to $84.7 \pm 3.8 \mathrm{mg} / \mathrm{dL}$ at 60 minutes and then returning to near baseline values of $91.9 \pm 3.6 \mathrm{mg} / \mathrm{dL}$ at 120 minutes (Figure $4 \mathrm{a}$ ). The associated area under the curve analysis illustrates how RYGB rats have markedly improved oral glucose tolerance compared with obese rats $(p<0.0001)$ being similar to that of lean rats (Figure $4 \mathrm{~b}$ ).

Concerning plasma insulin levels, obese rats were hyperinsulinemic at baseline $(1.2 \pm 0.2 \mathrm{nmol} / \mathrm{L})$, whereas both lean and RYGB rats had signficantly lower plasma insulin levels at baseline $(0.14 \pm 0.01$ $\mathrm{nmol} / \mathrm{L}$ and $0.39 \pm 0.07 \mathrm{nmol} / \mathrm{L} ; p<0.0001$ for both comparisons), which were statistically indistinguishable $(p=0.12)$ (Figure $4 \mathrm{c}$ ). During the OGTT, plasma insulin levels only slightly increased for lean rats peaking at $0.3 \pm 0.1 \mathrm{nmol} / \mathrm{L}$ by 15 minutes and then steadily declined to $0.1 \pm$ $0.02 \mathrm{nmol} / \mathrm{L}$ by 120 minutes. For obese rats, plasma insulin levels peaked at $1.9 \pm 0.4 \mathrm{nmol} / \mathrm{L}$ by 30 minutes and remained elevated at $1.6 \pm 0.3 \mathrm{mg} / \mathrm{dL}$ by 60 minutes before gradually declining to $0.9 \pm$ $0.1 \mathrm{nmol} / \mathrm{L}$ by 120 minutes (Figure 4c). Again, the plasma insulin curve for RYGB rats during the OGTT was qualitatively different from both lean and obese rats with plasma insulin levels peaking at $2.6 \pm 0.3 \mathrm{nmol} / \mathrm{L}$ by 15 minutes but remaining elevated at $2.4 \pm 0.3 \mathrm{nmol} / \mathrm{L}$ by 60 minutes before rapidly declining to near baseline levels of $0.48 \pm 0.07 \mathrm{nmol} / \mathrm{L}$ by 120 minutes (Figure $4 \mathrm{c}$ ). This is possibly due to the increased glucose-induced release of GLP-1, which is also an incretin, in RYGB rats. The associated area under the curve analysis suggests that RYGB rats might have improved insulin sensitivity compared with obese rats since their integrated plasma insulin levels throughout the OGTT were similar (Figure 4d) despite having markedly lower integrated blood glucose levels (Figure 4b). However, while HOMA-IR indices, as an indicator of insulin resistanace [65], were normalized in RYGB rats (Figure 4e), ISI-M indices, as an indicator of insulin sensitivity [66], were significantly higher for lean rats compared with both obese and RYGB rats $(p<0.0001$ for both comparisons), which were statistically indistinguishable from each other ( $p=0.67$ ) (Figure 4f). 
(a)

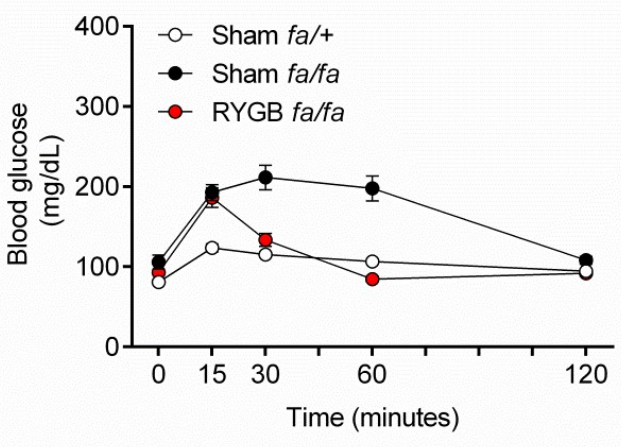

(c)

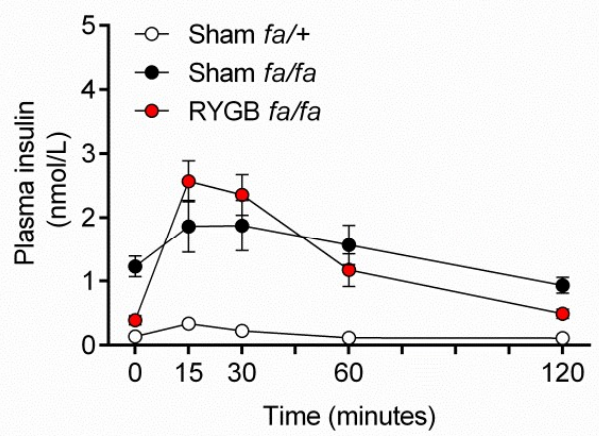

(e)

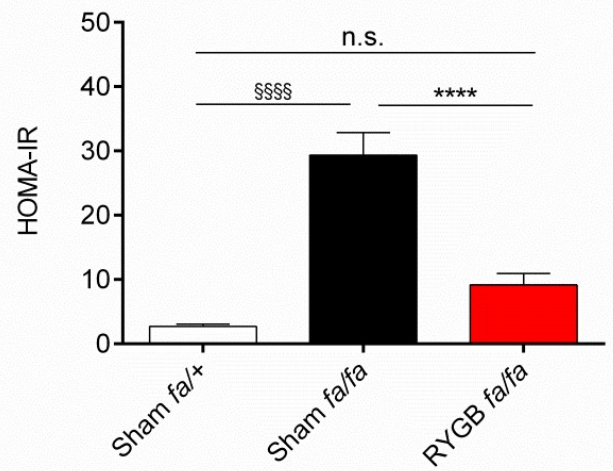

(b)

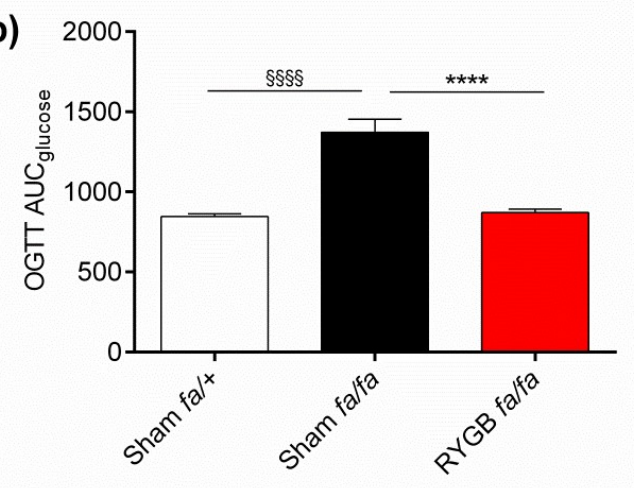

(d)

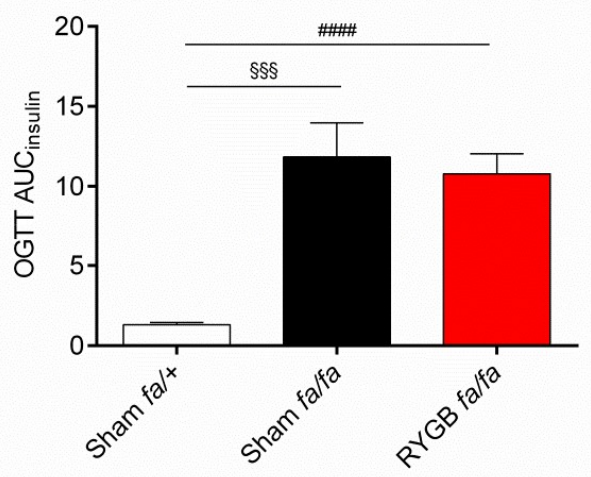

(f)

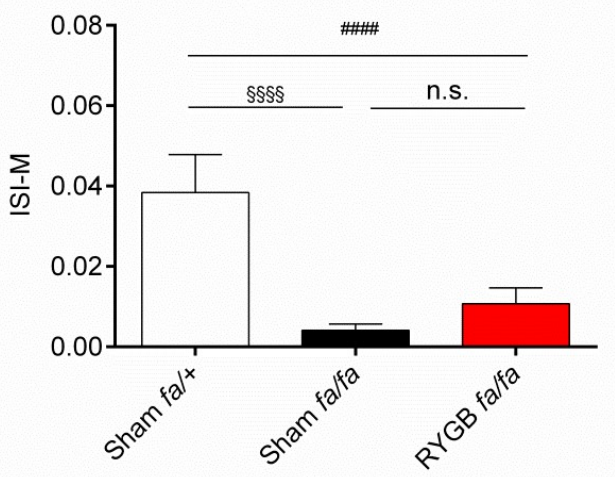

Figure 4. Intact leptin receptor signalling is not required for the improved glycemic control induced by RYGB

(a) Blood glucose, (b) the associated area under the curve (AUC), (c) plasma insulin and (d) the associated AUC during an oral glucose tolerance test in sham-operated fal+ rats $(n=12)$, sham-operated falfa rats $(n=12)$ and RYGB-operated falfa rats $(n=16)$ at postoperative day 27. (e) HOMA-IR and (f) ISI-M indices calculated from the rats in (a-d). Data are presented as mean \pm SEM. Statistical significance was determined by one-way ANOVA with Sidak post-hoc test. $s_{s s s} p<0.0001$ and $\$ s s p<0.001$ for sham-operated $f a /+$ vs. sham-operated $f a l f a$ rats, ${ }^{* * * *} p<0.0001$ for RYGB-operated $f a / f a$ vs. sham-operated falfa rats and ${ }^{\# \# \#} p<0.0001$ for RYGB-operated falfa vs. sham-operated fal+ rats. 


\section{Discussion}

Zucker Fatty $f a / f a$ rats harbor an autosomal recessive $A \rightarrow C$ point mutation at position 880 of the leptin receptor gene causing an inhibitory Glu $\rightarrow$ Ala amino acid substitution at position 269 in the extracellular domain of all leptin receptor subtypes [35-37], making them an established genetic model of leptin receptor deficiency. We formally assessed using these rats if enhanced endogenous leptin action is required for the sustained weight loss and food intake suppression as well as improved glycemic control characteristic of RYGB. We found that when applied to Zucker Fatty fa/fa rats, RYGB induced a $9.7 \%$ reduction in body weight that was stabilized at $-6.5 \%$ by the end of the 27 day monitoring period, and that food intake at this late time-point was $33.9 \%$ lower than that of sham-operated counterparts, normalizing to that of sham-operated Zucker Fatty fa/+ rats. By incorporating this important lean control group, we could further show that RYGB normalizes oral glucose tolerance independently of leptin receptor signalling and, by extension, enhanced leptin action.

The first studies aimed at assessing the necessity of leptin in the positive outcomes of RYGB on energy and glucose homeostasis utilized leptin-deficient $o b / o b$ mice [30,31]. Our findings contrast with those of Hao et al [30] who found that RYGB failed to induce sustained weight loss and food intake suppression as well as improved insulin sensitivity during the first six postoperative weeks in ob/ob mice. Our findings do, however, align with those of Mokadem et al [31] who found that RYGB induced sustained weight loss of $25-33 \%$ in $o b / o b$ mice by the sixth postoperative week, and reduced average food intake by $23 \%$, although unlike in their study, we could show that bodyweights of RYGB animals converged with that of lean controls. Another difference with Mokadem et al [31] is that RYGB failed to improve oral glucose tolerance in $o b / o b$ mice to the level of lean wild-type mice whereas we could show normalized oral glucose tolerance in our RYGB rats. The reasons for these discrepancies are unclear, but could be due to species differences or the degree of diminished leptin action between $o b / o b$ mouse (absolute) and Zucker Fatty $f a / f a$ rat (severely diminished) models. We do note, however, that while Zucker Fatty fa/fa rats reduce food intake upon central leptin administration at pharmacological doses [40,41], they fail to do so to peripherally administered leptin [41]. Therefore, it is unlikely that physiologically relevant (peripherally-derived) leptin action could be enhanced by RYGB in Zucker Fatty fa/fa rats. In this regard, our findings align with those from a study in leptin-unresponsive $d b / d b$ mice, which lack the intracellular signalling domain unique to leptin $b$ receptors due to an autosomal recessive $G \rightarrow T$ point mutation in the leptin receptor gene [11], in which the sustained weight loss induced by RYGB was preserved [33].

Because RYGB is technically more feasible to execute in rats than in mice, numerous studies have been performed aimed at assessing its metabolic effects in Zucker Fatty fa/fa [44-48] and Zucker Diabetic Fatty fa/fa [24, 49-64] rats. These studies, however, like those in $d b / d b$ mice [33,34], were not directly aimed at assessing the necessity of leptin receptors on the sustained weight loss and food intake suppression as well as improved glycemic control induced by RYGB, which is most likely why their details of food intake were either generally incomplete [44-51,54,61,62,64] or entirely missing [24,33,34,52,53,55-60,63], and their study conclusions were unrelated to leptin. Our findings contrast with the studies showing a lack of sustained weight loss after RYGB $[24,48,51,54,57,58,61,63]$, but are in line with the majority that do [45-47,49,50,52,55,59,62,64]. Further, our findings contrast with the study showing a lack of sustained food intake suppression induced by RYGB [48], but are consistent with those showing suppression of average food intake over the postoperative monitoring period $[46,49,50,54,61,62,64]$. Our study therefore extends previous work by showing a clear normalization of food intake induced by RYGB that is sustained at a late postoperative time-point when body weight is also normalized by the procedure.

With regards to improvements in glucose homeostasis induced by RYGB, we found a reduction of plasma insulin levels and HOMA-IR indices which is consistent with the studies on Zucker Fatty $f a / f a$ or Zucker Diabetic Fatty $f a / f a$ rats showing a reduction in blood glucose and/or plasma insulin 
levels $[24,45,47-52,54,55,59,62,64]$. Further, the improved oral glucose tolerance in our RYGB rats is in line with previous studies in which it was evaluated $[45,46,57,62]$. However, while ISI-M, as an indicator of insulin sensitivity [63], was not higher in RYGB-operated compared with sham-operated Zucker Fatty $f a / f a$ rats, a previous study on Zucker Diabetic Fatty fa/fa rats using hyperinsulinaemic-hyperglyecamic clamp showed that RYGB increases peripheral insulin sensitivity [57]. The discrepancies between rat studies can possibly be attributed to the differences in postoperative diets employed and monitoring periods as well as the RYGB model, which has varied considerably between laboratories since their inception [69].

If leptin is not an essential mediator of the sustained weight loss, food intake suppression and improved glycemic control induced by RYGB, then additional circulating and/or neural factors may be involved. We indeed confirmed that plasma levels of the anorexigenic and incretin gut hormone GLP-1 are increased by RYGB and could show that it negatively correlated with food intake and body weight at the time-point it was measured. However, numerous studies have shown that, like leptin, GLP-1 is also not an essential mediator of the sustained weight loss and food intake suppression as well as improved glycemic control induced by RYGB [70-74]. Therefore, other gut hormones and/or gut-derived microbiota products could be involved in mediating these cardinal metabolic benefits, which will be an important line of future investigation. Notably, Zucker Fatty $f a / f a$ or Zucker Diabetic Fatty $f a / f a$ rats may be the ideal model for such investigations, as food intake suppression in diet-induced obese mice and rats tends to diminish $[4,5,50,71,75,76]$ or are even absent $[30,61,74]$ after RYGB.

Strengths of our study include the well-powered group sizes allowing for robust statistical comparisons to be performed, as well as the incorporation of a lean control group. Another study strength is the detailed reporting of food intake absent in previous studies with Zucker Fatty fa/fa or Zucker Fatty Diabetic fa/fa rats. A limitation of our study is that despite achieving the degree of food intake suppression typically observed in the laboratory setting in patients after RYGB [73], the $30-40 \%$ weight loss characteristic of the procedure [77] wasn't. However, when factoring in the rapid weight gain of sham-operated Zucker Fatty fa/fa rats, RYGB-operated rats weighed $25.5 \pm 2.2 \%$ less which resembles the clinical outcome. Also, we did not directly compare the effects of RYGB on energy and glucose balance with a diet-induced obese group in which endogenous leptin action could be restored or enhanced as with previous the previous studies in $o b / o b$ mice [30,31]. Indeed, average daily food intake and hypothalamic leptin receptor signaling is normalized by RYGB in diet-induced obese Sprague Dawley rats, associated with normalized hypothalamic levels of protein tyrosine phosphatase 1B (PTP1B), a major inducer of central leptin resistance [12], although final body weights weren't reported in this particular study [78]. However, we recently showed in diet-induced obese Wistar rats under identical housing and surgical conditions as the present study, a similar degree of weight loss maintenance $(-6.1 \pm 1.3 \%)$ induced by RYGB as well as lower body weight compared to sham-operated counterparts $(-23.7 \pm 2.1 \%)$ [75], while others have shown a similar 13\% weight loss 11 days after RYGB in diet-induced obese Sprague Dawley compared with Zucker Diabetic Fatty $f a / f a$ rats [50] as well as similar body weight curves over a lengthier four week monitoring period [51,61]. Moreover, clinical studies have shown that both exogenous [79] and endogenous [80] leptin sensitivity are likely not enhanced by RYGB at later postoperative time points, which further argues against a critical role for leptin in the weight loss stability characteristic of the procedure.

In summary, we have presented further evidence against leptin being an essential mediator of the sustained weight loss, appetite suppression and improved glycemic control induced by RYGB, which instead points to additional circulating and/or neural factors. Our findings are thus consistent with the majority of previous studies in Zucker Fatty $f a / f a$ and Zucker Diabetic Fatty fa/fa rats as models of leptin receptor deficiency $[45-47,49,50,52,55,59,62,64]$, and place their findings in a new light. 
Author Contributions: “Conceptualization, M.K.H. and F.S.; methodology, C.C. and F.S.; software, M.K.H. and F.S.; validation, C.O.; formal analysis, M.K.H., A.H. and F.S.; investigation, L.R and A.N..; resources, F.S.; data curation, M.K.H. and F.S.; writing-original draft preparation, M.K.H. and F.S.; writing-review and editing, M.K.H, A.H. and F.S; visualization, M.K.H and F.S.; supervision, F.S. and C.O.; project administration, F.S. and C.O.; funding acquisition, F.S. All authors have read and agreed to the published version of the manuscript.

Funding: This publication was funded by the Interdisciplinary Center for Clinical Research of Wuerzburg (IZKF) (grant number Z-3/44), the German Research Foundation (DFG) and the University of Wuerzburg in the funding programme Open Access Publishing

Acknowledgments: We thank Manuela Hofmann and Bettina Porsch for skilled technical assistance with the experiments described in this manuscript.

Conflicts of Interest: The authors declare no conflict of interest and that the funders had no role in the design of the study; in the collection, analyses, or interpretation of data; in the writing of the manuscript, or in the decision to publish the results.

\section{References}

1. Arterburn, D.E.; Telem, D.A.; Kushner, R.F.; Courcoulas, A.P. Benefits and Risks of Bariatric Surgery in Adults: A Review. JAMA 2020, 324, 879-887, doi:10.1001/jama.2020.125672770015 [pii].

2. Evers, S.S.; Sandoval, D.A.; Seeley, R.J. The Physiology and Molecular Underpinnings of the Effects of Bariatric Surgery on Obesity and Diabetes. Annu Rev Physiol 2017, 79, 313-334, doi:10.1146/annurev-physiol-022516-034423.

3. Kwon, I.G.; Kang, C.W.; Park, J.P.; Oh, J.H.; Wang, E.K.; Kim, T.Y.; Sung, J.S.; Park, N.; Lee, Y.J.; Sung, H.J., et al. Serum glucose excretion after Roux-en-Y gastric bypass: a potential target for diabetes treatment. Gut 2020, doi:gutjnl-2020-321402 [pii]10.1136/gutjnl-2020-321402.

4. Li, K.; Zou, J.; Li, S.; Guo, J.; Shi, W.; Wang, B.; Han, X.; Zhang, H.; Zhang, P.; Miao, Z., et al. Farnesoid X receptor contributes to body weight-independent improvements in glycemic control after Roux-en-Y gastric bypass surgery in diet-induced obese mice. Mol Metab 2020, 37, 100980, doi:S2212-8778(20)30054-5 [pii]10.1016/j.molmet.2020.100980.

5. Ye, Y.; Abu El Haija, M.; Morgan, D.A.; Guo, D.; Song, Y.; Frank, A.; Tian, L.; Riedl, R.A.; Burnett, C.M.L.; Gao, Z., et al. Endocannabinoid Receptor-1 and Sympathetic Nervous System Mediate the Beneficial Metabolic Effects of Gastric Bypass. Cell Rep 2020, 33, 108270, doi:S2211-1247(20)31259-6 [pii]10.1016/j.celrep.2020.108270.

6. Friedman, J.M. Leptin and the endocrine control of energy balance. Nat Metab 2019, 1, 754-764, doi:10.1038/s42255-019-0095-y10.1038/s42255-019-0095-y [pii].

7. Seoane-Collazo, P.; Martinez-Sanchez, N.; Milbank, E.; Contreras, C. Incendiary Leptin. Nutrients 2020, 12, doi:E472 [pii]10.3390/nu12020472nu12020472 [pii].

8. Ingalls, A.M.; Dickie, M.M.; Snell, G.D. Obese, a new mutation in the house mouse. J Hered 1950, 41, 317-318, doi:10.1093/oxfordjournals.jhered.a106073.

9. Zhang, Y.; Proenca, R.; Maffei, M.; Barone, M.; Leopold, L.; Friedman, J.M. Positional cloning of the mouse obese gene and its human homologue. Nature 1994, 372, 425-432, doi:10.1038/372425a0.

10. Hummel, K.P.; Dickie, M.M.; Coleman, D.L. Diabetes, a new mutation in the mouse. Science 1966, 153, 1127-1128, doi:10.1126/science.153.3740.1127.

11. Chen, H.; Charlat, O.; Tartaglia, L.A.; Woolf, E.A.; Weng, X.; Ellis, S.J.; Lakey, N.D.; Culpepper, J.; Moore, K.J.; Breitbart, R.E., et al. Evidence that the diabetes gene encodes the leptin receptor: identification of a mutation in the leptin receptor gene in $\mathrm{db} / \mathrm{db}$ mice. Cell 1996, 84, 491-495, doi:S0092-8674(00)81294-5 [pii]10.1016/s0092-8674(00)81294-5.

12. Loh, K.; Fukushima, A.; Zhang, X.; Galic, S.; Briggs, D.; Enriori, P.J.; Simonds, S.; Wiede, F.; Reichenbach, A.; Hauser, C., et al. Elevated hypothalamic TCPTP in obesity contributes to cellular leptin resistance. Cell Metab 2011, 14, 684-699, doi:10.1016/j.cmet.2011.09.011S1550-4131(11)00357-3 [pii].

13. Olofsson, L.E.; Unger, E.K.; Cheung, C.C.; Xu, A.W. Modulation of AgRP-neuronal function by SOCS3 as an initiating event in diet-induced hypothalamic leptin resistance. Proc Natl Acad Sci U S A 2013, 110, E697-706, doi:10.1073/pnas.12182841101218284110 [pii]. 
14. Valdearcos, M.; Robblee, M.M.; Benjamin, D.I.; Nomura, D.K.; Xu, A.W.; Koliwad, S.K. Microglia dictate the impact of saturated fat consumption on hypothalamic inflammation and neuronal function. Cell Rep 2014, 9, 2124-2138, doi:10.1016/j.celrep.2014.11.018S2211-1247(14)00972-3 [pii].

15. Zhang, X.; Zhang, G.; Zhang, H.; Karin, M.; Bai, H.; Cai, D. Hypothalamic IKKbeta/NF-kappaB and ER stress link overnutrition to energy imbalance and obesity. Cell 2008, 135, 61-73, doi:10.1016/j.cell.2008.07.043S0092-8674(08)01008-8 [pii].

16. Halaas, J.L.; Gajiwala, K.S.; Maffei, M.; Cohen, S.L.; Chait, B.T.; Rabinowitz, D.; Lallone, R.L.; Burley, S.K.; Friedman, J.M. Weight-reducing effects of the plasma protein encoded by the obese gene. Science 1995, 269, 543-546, doi:10.1126/science.7624777.

17. Pelleymounter, M.A.; Cullen, M.J.; Baker, M.B.; Hecht, R.; Winters, D.; Boone, T.; Collins, F. Effects of the obese gene product on body weight regulation in ob/ob mice. Science 1995, 269, 540-543, doi:10.1126/science.7624776.

18. Feng, X.; Guan, D.; Auen, T.; Choi, J.W.; Salazar Hernandez, M.A.; Lee, J.; Chun, H.; Faruk, F.; Kaplun, E.; Herbert, Z., et al. IL1R1 is required for celastrol's leptin-sensitization and antiobesity effects. Nat Med 2019, 25, 575-582, doi:10.1038/s41591-019-0358-x10.1038/s41591-019-0358-x [pii].

19. Lee, J.; Liu, J.; Feng, X.; Salazar Hernandez, M.A.; Mucka, P.; Ibi, D.; Choi, J.W.; Ozcan, U. Withaferin A is a leptin sensitizer with strong antidiabetic properties in mice. Nat Med 2016, 22, 1023-1032, doi:10.1038/nm.4145nm.4145 [pii].

20. Arakawa, R.; Febres, G.; Cheng, B.; Krikhely, A.; Bessler, M.; Korner, J. Prospective study of gut hormone and metabolic changes after laparoscopic sleeve gastrectomy and Roux-en-Y gastric bypass. PLoS One 2020, 15, e0236133, doi:10.1371/journal.pone.0236133PONE-D-20-08332 [pii].

21. Salman, M.A.; El-Ghobary, M.; Soliman, A.; El Sherbiny, M.; Abouelregal, T.E.; Albitar, A.; Abdallah, A.; Mikhail, H.M.S.; Nafea, M.A.; Sultan, A., et al. Long-Term Changes in Leptin, Chemerin, and Ghrelin Levels Following Roux-en-Y Gastric Bypass and Laparoscopic Sleeve Gastrectomy. Obes Surg 2020, 30, 1052-1060, doi:10.1007/s11695-019-04254-z10.1007/s11695-019-04254-z [pii].

22. Unamuno, X.; Izaguirre, M.; Gomez-Ambrosi, J.; Rodriguez, A.; Ramirez, B.; Becerril, S.; Valenti, V.; Moncada, R.; Silva, C.; Salvador, J., et al. Increase of the Adiponectin/Leptin Ratio in Patients with Obesity and Type 2 Diabetes after Roux-en-Y Gastric Bypass. Nutrients 2019, 11, doi:E2069 [pii]10.3390/nu11092069nu11092069 [pii].

23. Guijarro, A.; Osei-Hyiaman, D.; Harvey-White, J.; Kunos, G.; Suzuki, S.; Nadtochiy, S.; Brookes, P.S.; Meguid, M.M. Sustained weight loss after Roux-en-Y gastric bypass is characterized by down regulation of endocannabinoids and mitochondrial function. Ann Surg 2008, 247, 779-790, doi:10.1097/SLA.0b013e318166fd5f00000658-200805000-00010 [pii].

24. Lau, R.G.; Kumar, S.; Hall, C.E.; Palaia, T.; Rideout, D.A.; Hall, K.; Brathwaite, C.E.; Ragolia, L. Roux-en-Y gastric bypass attenuates the progression of cardiometabolic complications in obese diabetic rats via alteration in gastrointestinal hormones. Surg Obes Relat Dis 2015, 11, 1044-1053, doi:10.1016/j.soard.2014.12.005S1550-7289(14)00485-7 [pii].

25. Lips, M.A.; Pijl, H.; van Klinken, J.B.; de Groot, G.H.; Janssen, I.M.; Van Ramshorst, B.; Van Wagensveld, B.A.; Swank, D.J.; Van Dielen, F.; Smit, J.W. Roux-en-Y gastric bypass and calorie restriction induce comparable time-dependent effects on thyroid hormone function tests in obese female subjects. Eur J Endocrinol 2013, 169, 339-347, doi:10.1530/EJE-13-0339EJE-13-0339 [pii].

26. Lips, M.A.; van Klinken, J.B.; Pijl, H.; Janssen, I.; Willems van Dijk, K.; Koning, F.; van Harmelen, V. Weight loss induced by very low calorie diet is associated with a more beneficial systemic inflammatory profile than by Roux-en-Y gastric bypass. Metabolism 2016, 65, 1614-1620, doi:S0026-0495(16)30086-5 [pii]10.1016/j.metabol.2016.07.013.

27. Neinast, M.D.; Frank, A.P.; Zechner, J.F.; Li, Q.; Vishvanath, L.; Palmer, B.F.; Aguirre, V.; Gupta, R.K.; Clegg, D.J. Activation of natriuretic peptides and the sympathetic nervous system following Roux-en-Y gastric bypass is associated with gonadal adipose tissues browning. Mol Metab 2015, 4, 427-436, doi:10.1016/j.molmet.2015.02.006S2212-8778(15)00042-3 [pii].

28. Olivan, B.; Teixeira, J.; Bose, M.; Bawa, B.; Chang, T.; Summe, H.; Lee, H.; Laferrere, B. Effect of weight loss by diet or gastric bypass surgery on peptide YY3-36 levels. Ann Surg 2009, 249, 948-953, doi:10.1097/SLA.0b013e3181a6cdb0.

29. Hankir, M.K.; Seyfried, F. Partial Leptin Reduction: An Emerging Weight Loss Paradigm. Trends Endocrinol Metab 2020, 31, 395-397, doi:S1043-2760(20)30055-2 [pii]10.1016/j.tem.2020.03.001.

30. Hao, Z.; Munzberg, H.; Rezai-Zadeh, K.; Keenan, M.; Coulon, D.; Lu, H.; Berthoud, H.R.; Ye, J. Leptin deficient $\mathrm{ob} / \mathrm{ob}$ mice and diet-induced obese mice responded differently to Roux-en-Y bypass surgery. Int J Obes (Lond) 2015, 39, 798-805, doi:10.1038/ijo.2014.189ijo2014189 [pii]. 
31. Mokadem, M.; Zechner, J.F.; Uchida, A.; Aguirre, V. Leptin Is Required for Glucose Homeostasis after Roux-en-Y Gastric Bypass in Mice. PLoS One 2015, 10, e0139960, doi:10.1371/journal.pone.0139960PONE-D-15-30424 [pii].

32. D'Souza A, M.; Neumann, U.H.; Glavas, M.M.; Kieffer, T.J. The glucoregulatory actions of leptin. Mol Metab 2017, 6, 1052-1065, doi:10.1016/j.molmet.2017.04.011S2212-8778(17)30175-8 [pii].

33. Liu, B.; Kuang, L.; Liu, J. Bariatric surgery relieves type 2 diabetes and modulates inflammatory factors and coronary endothelium eNOS/iNOS expression in db/db mice. Can J Physiol Pharmacol 2014, 92, 70-77, doi:10.1139/cjpp-2013-0034.

34. Huang, T.; Fu, J.; Zhang, Z.; Zhang, Y.; Liang, Y.; Ge, C.; Qin, X. Pancreatic islet regeneration through PDX-1/Notch-1/Ngn3 signaling after gastric bypass surgery in db/db mice. Exp Ther Med 2017, 14, 2831-2838, doi:10.3892/etm.2017.4896ETM-0-0-4896 [pii].

35. Chua, S.C., Jr.; White, D.W.; Wu-Peng, X.S.; Liu, S.M.; Okada, N.; Kershaw, E.E.; Chung, W.K.; Power-Kehoe, L.; Chua, M.; Tartaglia, L.A., et al. Phenotype of fatty due to Gln269Pro mutation in the leptin receptor (Lepr). Diabetes 1996, 45, 1141-1143, doi:10.2337/diab.45.8.1141.

36. Iida, M.; Murakami, T.; Ishida, K.; Mizuno, A.; Kuwajima, M.; Shima, K. Substitution at codon 269 (glutamine --> proline) of the leptin receptor (OB-R) cDNA is the only mutation found in the Zucker fatty (fa/fa) rat. Biochem Biophys Res Commun 1996, 224, 597-604, doi:S0006-291X(96)91070-0 [pii]10.1006/bbrc.1996.1070.

37. Phillips, M.S.; Liu, Q.; Hammond, H.A.; Dugan, V.; Hey, P.J.; Caskey, C.J.; Hess, J.F. Leptin receptor missense mutation in the fatty Zucker rat. Nat Genet 1996, 13, 18-19, doi:10.1038/ng0596-18.

38. Zucker, L.M.; Zucker, T.F. Fatty, a new mutation in the rat. Journal of Heredity 1961, 52, 275-278, doi:doi.org/10.1093/oxfordjournals.jhered.a107093.

39. Ionescu, E.; Sauter, J.F.; Jeanrenaud, B. Abnormal oral glucose tolerance in genetically obese (fa/fa) rats. Am J Physiol 1985, 248, E500-506, doi:10.1152/ajpendo.1985.248.5.E500.

40. Cusin, I.; Rohner-Jeanrenaud, F.; Stricker-Krongrad, A.; Jeanrenaud, B. The weight-reducing effect of an intracerebroventricular bolus injection of leptin in genetically obese fa/fa rats. Reduced sensitivity compared with lean animals. Diabetes 1996, 45, 1446-1450, doi:10.2337/diab.45.10.1446.

41. Dryden, S.; King, P.; Pickavance, L.; Doyle, P.; Williams, G. Divergent effects of intracerebroventricular and peripheral leptin administration on feeding and hypothalamic neuropeptide $Y$ in lean and obese (fa/fa) Zucker rats. Clin Sci (Lond) 1999, 96, 307-312, doi:10.1042/cs096030777184 [pii].

42. Griffen, S.C.; Wang, J.; German, M.S. A genetic defect in beta-cell gene expression segregates independently from the fa locus in the ZDF rat. Diabetes 2001, 50, 63-68, doi:10.2337/diabetes.50.1.63.

43. Clark, J.B.; Palmer, C.J.; Shaw, W.N. The diabetic Zucker fatty rat. Proc Soc Exp Biol Med 1983, 173, 68-75, doi:10.3181/00379727-173-41611.

44. Bankoglu, E.E.; Seyfried, F.; Rotzinger, L.; Nordbeck, A.; Corteville, C.; Jurowich, C.; Germer, C.T.; Otto, C.; Stopper, H. Impact of weight loss induced by gastric bypass or caloric restriction on oxidative stress and genomic damage in obese Zucker rats. Free Radic Biol Med 2016, 94, 208-217, doi:10.1016/j.freeradbiomed.2016.02.033S0891-5849(16)00092-7 [pii].

45. Meirelles, K.; Ahmed, T.; Culnan, D.M.; Lynch, C.J.; Lang, C.H.; Cooney, R.N. Mechanisms of glucose homeostasis after Roux-en-Y gastric bypass surgery in the obese, insulin-resistant Zucker rat. Ann Surg 2009, 249, 277-285, doi:10.1097/SLA.0b013e3181904af000000658-200902000-00016 [pii].

46. Seyfried, F.; Miras, A.D.; Rotzinger, L.; Nordbeck, A.; Corteville, C.; Li, J.V.; Schlegel, N.; Hankir, M.; Fenske, W.; Otto, C., et al. Gastric Bypass-Related Effects on Glucose Control, beta Cell Function and Morphology in the Obese Zucker Rat. Obes Surg 2016, 26, 1228-1236, doi:10.1007/s11695-015-1882-510.1007/s11695-015-1882-5 [pii].

47. Wolff, B.S.; Meirelles, K.; Meng, Q.; Pan, M.; Cooney, R.N. Roux-en-Y gastric bypass alters small intestine glutamine transport in the obese Zucker rat. Am J Physiol Gastrointest Liver Physiol 2009, 297, G594-601, doi:10.1152/ajpgi.00104.200900104.2009 [pii].

48. Xu, Y.; Ohinata, K.; Meguid, M.M.; Marx, W.; Tada, T.; Chen, C.; Quinn, R.; Inui, A. Gastric bypass model in the obese rat to study metabolic mechanisms of weight loss. J Surg Res 2002, 107, 56-63, doi:S002248040296508X [pii]10.1006/jsre.2002.6508.

49. Abegg, K.; Corteville, C.; Docherty, N.G.; Boza, C.; Lutz, T.A.; Munoz, R.; le Roux, C.W. Effect of bariatric surgery combined with medical therapy versus intensive medical therapy or calorie restriction and weight loss on glycemic control in Zucker diabetic fatty rats. Am J Physiol Regul Integr Comp Physiol 2015, 308, R321-329, doi:10.1152/ajpregu.00331.2014ajpregu.00331.2014 [pii].

50. Bhutta, H.Y.; Deelman, T.E.; le Roux, C.W.; Ashley, S.W.; Rhoads, D.B.; Tavakkoli, A. Intestinal sweet-sensing pathways and metabolic changes after Roux-en-Y gastric bypass surgery. Am J Physiol Gastrointest Liver Physiol 2014, 307, G588-593, doi:10.1152/ajpgi.00405.2013ajpgi.00405.2013 [pii]. 
51. Bhutta, H.Y.; Rajpal, N.; White, W.; Freudenberg, J.M.; Liu, Y.; Way, J.; Rajpal, D.; Cooper, D.C.; Young, A.; Tavakkoli, A., et al. Effect of Roux-en-Y gastric bypass surgery on bile acid metabolism in normal and obese diabetic rats. PLoS One 2015, 10, e0122273, doi:10.1371/journal.pone.0122273PONE-D-14-42268 [pii].

52. Canney, A.L.; Cohen, R.V.; Elliott, J.A.; C, M.A.; Martin, W.P.; Docherty, N.G.; le Roux, C.W. Improvements in diabetic albuminuria and podocyte differentiation following Roux-en-Y gastric bypass surgery. Diab Vasc Dis Res 2020, 17, 1479164119879039, doi:10.1177/1479164119879039.

53. Guo, Y.; Liu, C.Q.; Liu, G.P.; Huang, Z.P.; Zou, D.J. Roux-en-Y gastric bypass decreases endotoxemia and inflammatory stress in association with improvements in gut permeability in obese diabetic rats. $J$ Diabetes 2019, 11, 786-793, doi:10.1111/1753-0407.12906.

54. Guo, Y.; Liu, C.Q.; Shan, C.X.; Chen, Y.; Li, H.H.; Huang, Z.P.; Zou, D.J. Gut microbiota after Roux-en-Y gastric bypass and sleeve gastrectomy in a diabetic rat model: Increased diversity and associations of discriminant genera with metabolic changes. Diabetes Metab Res Rev 2017, 33, doi:10.1002/dmrr.2857.

55. Huang, H.; Aminian, A.; Hassan, M.; Dan, O.; Axelrod, C.L.; Schauer, P.R.; Brethauer, S.A.; Kirwan, J.P. Gastric Bypass Surgery Improves the Skeletal Muscle Ceramide/S1P Ratio and Upregulates the AMPK/ SIRT1/ PGC-1alpha Pathway in Zucker Diabetic Fatty Rats. Obes Surg 2019, 29, 2158-2165, doi:10.1007/s11695-019-03800-z10.1007/s11695-019-03800-z [pii].

56. Kumar, S.; Lau, R.; Hall, C.; Palaia, T.; Brathwaite, C.E.; Ragolia, L. Bile acid elevation after Roux-en-Y gastric bypass is associated with cardio-protective effect in Zucker Diabetic Fatty rats. Int J Surg 2015, 24, 70-74, doi:10.1016/j.ijsu.2015.11.010S1743-9191(15)01314-X [pii].

57. Mocanu, A.O.; Mulya, A.; Huang, H.; Dan, O.; Schauer, P.R.; Dinischiotu, A.; Brethauer, S.A.; Kirwan, J.P. Effect of Roux-en-Y Gastric Bypass on the NLRP3 Inflammasome in Pancreatic Islets from Zucker Diabetic Fatty Rats. Obes Surg 2016, 26, 3076-3081, doi:10.1007/s11695-016-2373-z10.1007/s11695-016-2373-z [pii].

58. Mosinski, J.D.; Aminian, A.; Axelrod, C.L.; Batayyah, E.; Talamas, H.R.; Daigle, C.; Mulya, A.; Scelsi, A.R.; Schauer, P.R.; Brethauer, S., et al. Roux-en-Y Gastric Bypass Restores Islet Function and Morphology Independent of Body Weight in ZDF Rats. Am J Physiol Endocrinol Metab 2021, doi:10.1152/ajpendo.00467.2020.

59. Nair, M.; Martin, W.P.; Zhernovkov, V.; Elliott, J.A.; Fearon, N.; Eckhardt, H.; McCormack, J.; Godson, C.; Brennan, E.P.; Fandriks, L., et al. Characterization of the renal cortical transcriptome following Roux-en-Y gastric bypass surgery in experimental diabetic kidney disease. BMJ Open Diabetes Res Care 2020, 8, doi:e001113 [pii]10.1136/bmjdrc-2019-0011138/1/e001113 [pii].

60. Pal, A.; Rhoads, D.B.; Tavakkoli, A. Effect of Portal Glucose Sensing on Systemic Glucose Levels in SD and ZDF Rats. PLoS One 2016, 11, e0165592, doi:10.1371/journal.pone.0165592PONE-D-16-30977 [pii].

61. Pal, A.; Rhoads, D.B.; Tavakkoli, A. Portal milieu and the interplay of multiple antidiabetic effects after gastric bypass surgery. Am J Physiol Gastrointest Liver Physiol 2019, 316, G668-G678, doi:10.1152/ajpgi.00389.2018.

62. Shimizu, H.; Eldar, S.; Heneghan, H.M.; Schauer, P.R.; Kirwan, J.P.; Brethauer, S.A. The effect of selective gut stimulation on glucose metabolism after gastric bypass in the Zucker diabetic fatty rat model. Surg Obes Relat Dis 2014, 10, 29-35, doi:10.1016/j.soard.2013.01.021S1550-7289(13)00042-7 [pii].

63. Vangoitsenhoven, R.; Mulya, A.; Mosinski, J.D.; Brethauer, S.A.; Schauer, P.R.; Kirwan, J.P.; Aminian, A. Effects of gastric bypass surgery on expression of glucose transporters and fibrotic biomarkers in kidney of diabetic fatty rats. Surg Obes Relat Dis 2020, 16, 1242-1248, doi:S1550-7289(20)30201-X [pii]10.1016/j.soard.2020.04.017.

64. Seyfried, F.; Bueter, M.; Spliethoff, K.; Miras, A.D.; Abegg, K.; Lutz, T.A.; le Roux, C.W. Roux-en Y gastric bypass is superior to duodeno-jejunal bypass in improving glycaemic control in Zucker diabetic fatty rats. Obes Surg 2014, 24, 1888-1895, doi:10.1007/s11695-014-1301-3.

65. Matthews, D.R.; Hosker, J.P.; Rudenski, A.S.; Naylor, B.A.; Treacher, D.F.; Turner, R.C. Homeostasis model assessment: insulin resistance and beta-cell function from fasting plasma glucose and insulin concentrations in man. Diabetologia 1985, 28, 412-419, doi:10.1007/BF00280883.

66. Matsuda, M.; DeFronzo, R.A. Insulin sensitivity indices obtained from oral glucose tolerance testing: comparison with the euglycemic insulin clamp. Diabetes Care 1999, 22, 1462-1470, doi:10.2337/diacare.22.9.1462.

67. Miras, A.D.; Seyfried, F.; Phinikaridou, A.; Andia, M.E.; Christakis, I.; Spector, A.C.; Botnar, R.M.; le Roux, C.W. Rats fed diets with different energy contribution from fat do not differ in adiposity. Obes Facts 2014, 7, 302-310, doi:10.1159/000368622000368622 [pii].

68. Moffett, R.C.; Docherty, N.G.; le Roux, C.W. The altered enteroendocrine reportoire following roux-en-Y-gastric bypass as an effector of weight loss and improved glycaemic control. Appetite 2021, 156, 104807, doi:S0195-6663(19)30753-6 [pii]10.1016/j.appet.2020.104807. 
69. Seyfried, F.; le Roux, C.W.; Bueter, M. Lessons learned from gastric bypass operations in rats. Obes Facts 2011, 4 Suppl 1, 3-12, doi:10.1159/000327301000327301 [pii].

70. Carmody, J.S.; Munoz, R.; Yin, H.; Kaplan, L.M. Peripheral, but not central, GLP-1 receptor signaling is required for improvement in glucose tolerance after Roux-en-Y gastric bypass in mice. Am J Physiol Endocrinol Metab 2016, 310, E855-861, doi:10.1152/ajpendo.00412.2015ajpendo.00412.2015 [pii].

71. Mokadem, M.; Zechner, J.F.; Margolskee, R.F.; Drucker, D.J.; Aguirre, V. Effects of Roux-en-Y gastric bypass on energy and glucose homeostasis are preserved in two mouse models of functional glucagon-like peptide-1 deficiency. Mol Metab 2014, 3, 191-201, doi:10.1016/j.molmet.2013.11.010S2212-8778(13)00128-2 [pii].

72. Osto, E.; Doytcheva, P.; Corteville, C.; Bueter, M.; Dorig, C.; Stivala, S.; Buhmann, H.; Colin, S.; Rohrer, L.; Hasballa, R., et al. Rapid and body weight-independent improvement of endothelial and high-density lipoprotein function after Roux-en-Y gastric bypass: role of glucagon-like peptide-1. Circulation 2015, 131, 871-881, doi:10.1161/CIRCULATIONAHA.114.011791CIRCULATIONAHA.114.011791 [pii].

73. Svane, M.S.; Jorgensen, N.B.; Bojsen-Moller, K.N.; Dirksen, C.; Nielsen, S.; Kristiansen, V.B.; Torang, S.; Wewer Albrechtsen, N.J.; Rehfeld, J.F.; Hartmann, B., et al. Peptide YY and glucagon-like peptide-1 contribute to decreased food intake after Roux-en-Y gastric bypass surgery. Int J Obes (Lond) 2016, 40, 1699-1706, doi:10.1038/ijo.2016.121ijo2016121 [pii].

74. Ye, J.; Hao, Z.; Mumphrey, M.B.; Townsend, R.L.; Patterson, L.M.; Stylopoulos, N.; Munzberg, H.; Morrison, C.D.; Drucker, D.J.; Berthoud, H.R. GLP-1 receptor signaling is not required for reduced body weight after RYGB in rodents. Am J Physiol Regul Integr Comp Physiol 2014, 306, R352-362, doi:10.1152/ajpregu.00491.2013ajpregu.00491.2013 [pii].

75. Dischinger, U.; Corteville, C.; Otto, C.; Fassnacht, M.; Seyfried, F.; Hankir, M.K. GLP-1 and PYY3-36 reduce high-fat food preference additively after Roux-en-Y gastric bypass in diet-induced obese rats. Surg Obes Relat Dis 2019, 15, 1483-1492, doi:S1550-7289(19)30144-3 [pii]10.1016/j.soard.2019.04.008.

76. Shin, A.C.; Zheng, H.; Townsend, R.L.; Sigalet, D.L.; Berthoud, H.R. Meal-induced hormone responses in a rat model of Roux-en-Y gastric bypass surgery. Endocrinology 2010, 151, 1588-1597, doi:10.1210/en.2009-1332en.2009-1332 [pii].

77. Adams, T.D.; Davidson, L.E.; Litwin, S.E.; Kim, J.; Kolotkin, R.L.; Nanjee, M.N.; Gutierrez, J.M.; Frogley, S.J.; Ibele, A.R.; Brinton, E.A., et al. Weight and Metabolic Outcomes 12 Years after Gastric Bypass. N Engl J Med 2017, 377, 1143-1155, doi:10.1056/NEJMoa1700459.

78. Liu, J.Y.; Mu, S.; Zhang, S.P.; Guo, W.; Li, Q.F.; Xiao, X.Q.; Zhang, J.; Wang, Z.H. Roux-en-Y gastric bypass surgery suppresses hypothalamic PTP1B protein level and alleviates leptin resistance in obese rats. Exp Ther Med 2017, 14, 2536-2542, doi:10.3892/etm.2017.4801ETM-0-0-4801 [pii].

79. Korner, J.; Conroy, R.; Febres, G.; McMahon, D.J.; Conwell, I.; Karmally, W.; Aronne, L.J. Randomized double-blind placebo-controlled study of leptin administration after gastric bypass. Obesity (Silver Spring) 2013, 21, 951-956, doi:10.1002/oby.20433.

80. Ceccarini, G.; Pelosini, C.; Ferrari, F.; Magno, S.; Vitti, J.; Salvetti, G.; Moretto, C.; Marioni, A.; Buccianti, P.; Piaggi, P., et al. Serum IGF-binding protein 2 (IGFBP-2) concentrations change early after gastric bypass bariatric surgery revealing a possible marker of leptin sensitivity in obese subjects. Endocrine 2019, 65, 86-93, doi:10.1007/s12020-019-01915-y10.1007/s12020-019-01915-y [pii]. 